\title{
Improving Informed Consent for Novel Vaccine Research in a Pediatric Hospital Setting Using a Blended Research-Design Approach
}

\section{OPEN ACCESS}

Edited by:

Marzia Duse,

Sapienza University of Rome, Italy

Reviewed by:

Michael Barrett,

University College Dublin, Ireland

Sonia Dahan

Aix Marseille Université, France

*Correspondence:

Sally M. Jackson

sallymjackson@gmail.com

Specialty section:

This article was submitted to General Pediatrics and Pediatric

Emergency Care,

a section of the journal

Frontiers in Pediatrics

Received: 16 December 2019

Accepted: 22 September 2020

Published: 12 January 2021

Citation:

Jackson SM, Daverio M, Perez SL, Gesualdo F and Tozzi AE (2021) Improving Informed Consent for Novel Vaccine Research in a Pediatric Hospital Setting Using a Blended

Research-Design Approach.

Front. Pediatr. 8:520803.

doi: 10.3389/fped.2020.520803

\section{Sally M. Jackson ${ }^{1 *}$, Margherita Daverio ${ }^{2}$, Silvia Lorenzo Perez ${ }^{3}$, Francesco Gesualdo ${ }^{1}$ and} Alberto E. Tozzi ${ }^{1}$

${ }^{1}$ Multifactorial and Complex Diseases Research Area, Bambino Gesù Children's Hospital IRCCS, Rome, Italy, ${ }^{2}$ Libera Università Maria SS. Assunta, Rome, Italy, ${ }^{3}$ AND Consulting Group, Brussels, Belgium

It is necessary to conduct Clinical Trials in children, including for novel vaccines. Children cannot legally provide valid consent, but can assent to research participation. Informed consent and assent communications are frequently criticized for their lack of comprehensibility and often, researchers do not involve patients in informed consent design. We tested a blended research-design approach to co-design multimedia informed consent prototypes for experimental vaccine studies targeted at the pediatric population. We report details on the methodology utilized, and the insights, ideas, and prototype solutions we generated using social media data analysis, a survey, and workshops. A survey of clinical trial researchers indicated that while the most did not use technology for informed consent, they considered its utilization favorable. Social media analysis enabled researchers to quickly understand where community perspectives were concordant and discordant and build their understanding of the types of topics that they may want to focus on during the design workshops. Participatory design workshops for children and their families reaped insights, ideas, and prototypes for a range of tools including apps and websites. Participants felt that the prototypes were better able to communicate necessary content than the original text document format. We propose using a participatory, mixed-methods approach to design informed consent so that it is better adapted to patients' needs. Such an approach would be helpful in better addressing the needs of different segments of the populations involved in clinical trials. Further evidence should be gained about the impact of this strategy in improving recruitment, decreasing withdrawals and litigations, and improving patient satisfaction during clinical trials.

Keywords: informed consent, ethics, mixed-methods, clinical research, natural language processing (nlp), design thinking (DT), vaccination, inclusion 


\section{INTRODUCTION}

Legal attempts to improve transparency $(1,2)$ have increased the amount of information disclosed to research participants through informed consent documents, which have become increasingly lengthy and complex $(3,4)$. According to EU Regulation, informed consent needs to be concise to be understandable (2) yet comprehensiveness and conciseness are conflicting needs that can lead to poor communication at a time when potential research participants are making an important decision about their health $(5,6)$.

Clinical trials are frequently necessary in children at different growth and developmental stages due to children's diverse needs which differ to adults (7-13). As the ability to understand complex information evolves with age and children are less likely than adults to be able to express their needs and defend their interests, they are considered less able to give consent (12), and do not have the legal capacity to do it (2). Researchers are obliged to obtain consent from parents or legal representatives, and children can provide assent appropriate to their age and maturity (14). Researchers, legislators, parents, and children differ in opinion about which information is most relevant to include, as well as mechanism of delivery (15-17). Emotion and trust play a strong role in decision making, particularly with children (18).

Advances in technology have led to new opportunities to support the informed consent and assent process (19). Participatory methods have previously been proposed to involve patients in informed consent and assent design (20). To cocreate informed consent with participants, we looked to "design thinking" (DT). DT is a user-centered $(21,22)$ participatory approach used to creatively address complex problems. It is increasingly being utilized in a wide range of health domains at the individual (e.g., disease prevention and health management) and the system levels (e.g., health care management and organizational change) (23-26).

DT is based upon three main pillars-empathy, collaboration, and experimentation (21). The priority that DT places on end-users' desires, needs, and challenges, results in a better understanding of the problem in order to develop more comprehensive and effective solutions (27). Multidisciplinary teams are compiled and then prompted to generate a large number of ideas which are honed, and prototypes are rapidly developed and tested $(22,28,29)$. Rapid cycles of insight and idea generation, testing, and prototyping reduce the timeframe for design and implementation (30).

In mid-2019, we tested a blended research-design approach to co-design multimedia informed consent prototypes for experimental vaccine studies targeted at the pediatric population. In the present article, we report details on the methodology utilized, and the insights, ideas, and prototype solutions we generated using social media data analysis, a survey, and workshops.

\section{MATERIALS AND METHODS}

The study was led by an interdisciplinary team at our 600-bed academic teaching hospital, Bambino Gesù Children's Hospital
(OPBG), in Rome, Italy, funded by EU Horizon 2020 framework under the i-Consent Project (Grant Agreement 741856), in collaboration with LUMSA University i-Consent unit in Rome.

Principles from IDEO's design thinking approach (31) were blended with a mix of qualitative and quantitative research methods to generate inclusive informed consent prototypes for vaccine clinical trials targeting pediatric patients.

Insight generation was conducted through social media analysis, a survey, and workshops, focused on the lenses of culture and age. Workshops also included idea generation and prioritization, and prototyping phases (Figure 1). The value of the proposed methodology for improving informed consent was discussed with experts in informed consent during meetings of the i-Consent project.

\section{Ethics Statement}

Design thinking activities were conducted in compliance with the ethical requirements set out in i-Consent Project (Grant Agreement 741856) work package 6 ("Ethics requirements"). Workshop and survey participants provided informed consent that was prepared in accordance with the project ethical requirements. Facebook data was acquired from posts with public privacy settings.

\section{Social Media Analysis}

Design Thinking frequently seeks the perspectives of users at different ends of a spectrum $(32,33)$. We therefore wanted to use natural language processing to rapidly identify posts on public Facebook pages that would give us rapid insights relevant for the design of vaccine clinical trials communications.

The Facebook search function was used in April and May 2019 with words for "vaccination" and "children" in English and Italian. Data scientists identified posts that they perceived to be of highest relevance and engagement. Data were retrieved from posts using a Facepager (34) scraper, and stored in an SQL database. Data considered relevant were text, photos, or videos, the timestamp, number of reactions (e.g., comments or likes), and the hierarchical-level of the comment (e.g., 0 for initial post, 1 for first-level comment, and 2 for comments responding to first-level comments). Python 3.6 was used to pre-process and clean data: comments containing only emoticons, stickers, or mentions of users were deleted. Polyglot is a popular natural language pipeline for Python that can assign a polarity score to a given sentence: comments were given a positive score if the polarity score is greater or equal to 1 , negative if the polarity score is lower or equal to -1 , and neutral if the polarity score was 0 . The score was visualized enabling the identification of high polarity (positive and negative), or "extreme" comments. Qualitative thematic analysis was conducted on the most polarized comments. Journalistic analysis was used to follow posts and their trajectory in real-time.

\section{Survey}

An online survey including numerical, categorical, binary, multiple choice, and open questions, on the use of technology for informed consent was developed using Survey Monkey, and the survey link circulated by e-mail to clinical trial researchers 


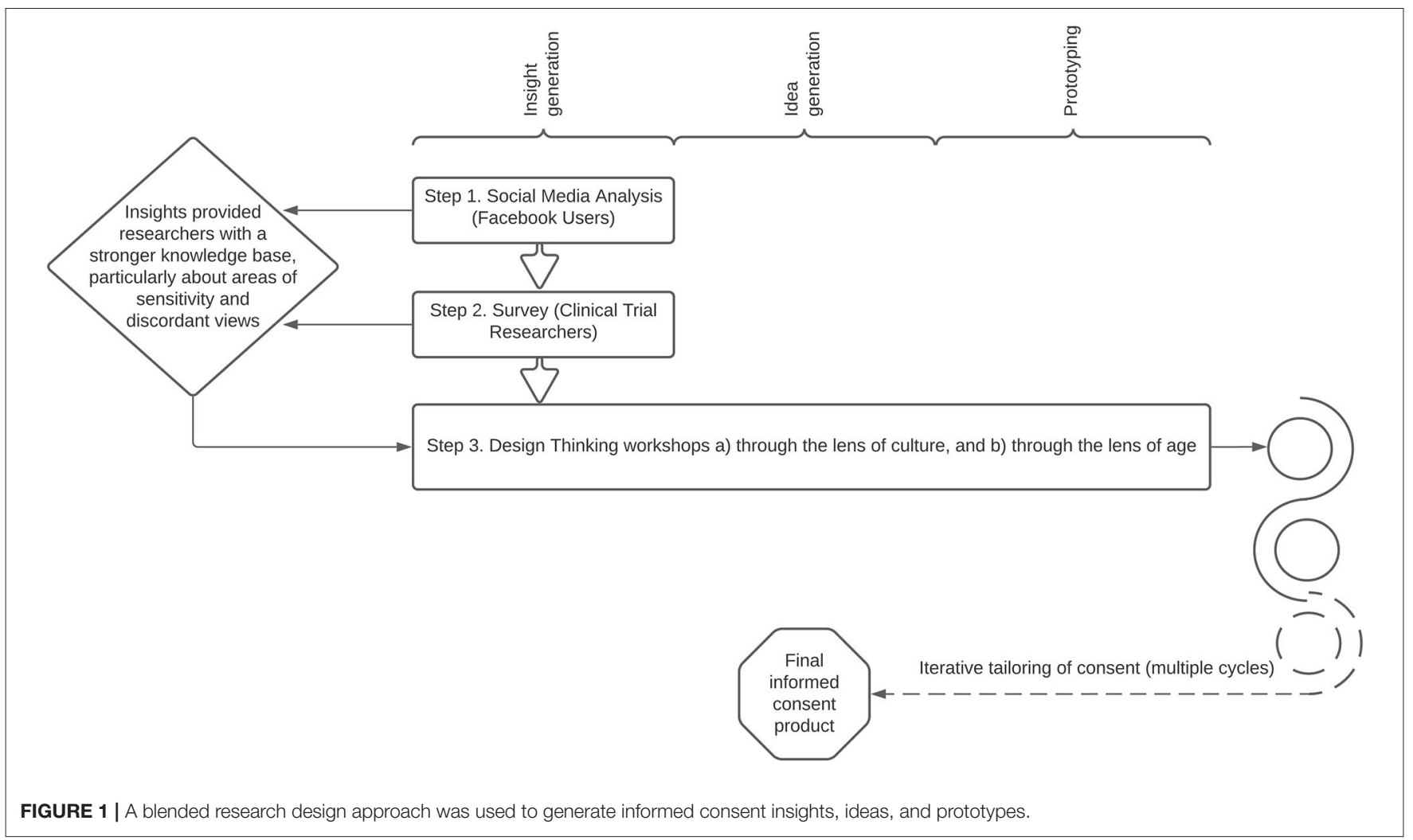

within i-Consent consortium network in Spain and the UK in May and June 2019. Participants were asked about how they currently use technology for the communication of information to participants, their perspectives of how technology could potentially be used, how they felt clinical trial participants could benefit from technology, and how they felt about using the technology themselves. Responses were completely anonymized, and were downloaded into an Excel spreadsheet and descriptive analyses were conducted.

\section{Workshops}

\section{Workshop Group 1: The Lens of Culture}

Parents $(n=2)$, cultural mediators $(n=6)$ with diverse backgrounds, researchers $(n=3)$, clinicians $(n=3)$, and ethics experts $(n=2)$ were recruited from Bambino Gesù Children's Hospital (OPBG), LUMSA University, and Salute Migranti Forzati Roma (SAMIFO), an institution that supports forced migrants to attain healthcare in Rome's health system.

Two workshops were held. In the first, the facilitator encouraged empathy by describing a scenario where a teenage girl was invited to part in a hypothetical vaccine trial of a currently unlicensed human papillomavirus vaccine, and then recreating the girls' user journey. The group was provided with (a) a hypothetical invite letter and (b) sections of a hypothetical informed consent document related to vaccine receipt, sideeffects, sexual health, and data/privacy. Both documents were based upon informed consent materials that had been used at OPBG for randomized clinical trials. Participants were asked to add statements to an empathy map-a collaborative tool inspired by IDEO and developed at Stanford d.school to help synthesize participants thoughts and feelings (35). The facilitator discussed the comments with the group, particularly noting where they converged and diverged, to develop consensus on the priority problems in the document. IDEO brainstorm rules (36) were applied to generate ideas for solutions. After the first workshop, a researcher entered the participants' comments into an excel spreadsheet and conducted qualitative thematic analysis to identify document modifications considered necessary by the participants. The document was then rewritten accordingly.

In the second workshop, participants were divided into 4 groups with the objective to develop wireframe prototypes. Each group was provided with both the old and the modified document text and craft materials, and asked to create a prototype for an improved informed consent for their choice of technology. Each group presented their prototype explaining its structural features and the reasons behind modifications made to the text.

\section{Workshop Group 2: The Lens of Age}

Four children aged 11-14 (1 with cystic fibrosis, 3 healthy) and four parents were recruited from Bambino Gesù Children's Hospital (OPBG). A role-play was conducted to introduce participants to, and develop empathy for the following persona and scenario: A healthy child who learns about and consents to an experimental vaccine trial, then, after receiving the injection, returns home and develops a low fever. Children were asked 
TABLE 1 | Descriptive characteristics of four selected Facebook posts in Italy and the UK.

\begin{tabular}{|c|c|c|c|c|}
\hline Facebook page & \multicolumn{2}{|c|}{ La Repubblica } & BBC & Italian Society of Pediatrics \\
\hline Topic & \multicolumn{2}{|c|}{ The importance of giving vaccines to children } & $\begin{array}{l}\text { The link between HPV vaccine and } \\
\text { a drop in cervical disease (text) }\end{array}$ & $\begin{array}{l}\text { The importance of getting vaccinated } \\
\text { against pertussis during pregnancy }\end{array}$ \\
\hline Format & \multicolumn{2}{|l|}{ Text and video } & Text & Text \\
\hline User interaction mode & \multicolumn{2}{|l|}{ Passive } & Passive & $\begin{array}{l}\text { Active: invited pregnant women to get a } \\
\text { vaccine and take and post a selfie. }\end{array}$ \\
\hline Date of post & 8 May $2017^{1}$ & 8 May $2018^{2}$ & 4 April $2019^{3}$ & 23 April $2019^{4}$ \\
\hline Reactions ( $(n)$ & $2.1 \mathrm{k}$ & $2.3 \mathrm{k}$ & $22 \mathrm{k}$ & 287 \\
\hline Comments $(n)$ & 988 & 369 & $1.7 \mathrm{k}$ & 404 \\
\hline Shares $(n)$ & 852 & 737 & $6.6 \mathrm{k}$ & 678 \\
\hline Average polarity score & 0.27 & 0.48 & -0.8 & -0.12 \\
\hline Proportion of positive comments (\%) & 53.6 & 56.6 & 35.4 & 49.7 \\
\hline
\end{tabular}

${ }^{1}$ https://www.facebook.com/179618821150/posts/10155487940361151?sfns $=x m w a$.

${ }^{2}$ https://www.facebook.com/179618821150/posts/10157752802101151? sfns $=x m w a$.

${ }^{3}$ https://www.facebook.com/228735667216/posts/10156595513227217?sfns $=x m w a$.

${ }^{4}$ https://www.facebook.com/295443760472888/posts/2643171269033447?sfns=cwmo.

to express their feelings through the creation of balloon faces and empathy maps. A selection of tools including specialized applications and bots, as well as video call, voice call, and SMS, were presented to the children as potential options for the delivery of informed consent information. Children were taken along the user journey and asked to vote on which type of multimedia format they would prefer to use at different stages of the scenario. The group was then split into non-familial childadult pairs, and each pair was asked to create prototype text scripts between the patient and the clinical researcher for their preferred multimedia type.

\section{RESULTS}

\section{Social Media Analysis}

Based on the search conducted through Facebook, 4 posts of high engagement and relevance were selected. Posts were extracted from two major news sites, La Repubblica in Italy and the BBC in the UK, and from the Facebook page of the Italian Society of Pediatrics (SIP). Two posts were extracted from the Facebook page of La Repubblica-two identical posts published one year apart-on the importance of giving vaccines to children. One post was extracted from the BBC Facebook page that was about the link between HPV vaccine and a drop in cervical disease. The last post was extracted from the page of the Italian Society of Pediatrics (SIP) and it was about the importance of getting vaccinated against pertussis during pregnancy.

Descriptive characteristics, extracted using NLP, and polarity scores of the selected posts are presented in Table 1 . The polarity distribution of the comments as determined by NLP is provided in Figure 2. By following the ISP post journalistically, it was evident that reactions were positive until it was re-posted onto the page of an anti-vaccine group, upon which comments became strongly negative.

Positive and negative comments with the most extreme values were then selected and compared qualitatively to enable researchers to quickly understand where perspectives were concordant and discordant between people with extreme views and build their understanding of the types of topics that they may want to focus on during the design workshops.

An example of concordance on the BBC HPV vaccine post was that both positive and negative extremes said that they would let the daughter decide for herself. An example of discordance was “The vaccine was pretty new I didn't know whether it would work or not I didn't know what kind of reaction she would have to it" from the positive extreme, and "Most cervical cancer is not caused by this virus. In fact there has never been a cause and effect relationship between this virus and cancer-only correlational data" from the negative extreme.

\section{Survey}

Thirty Clinical Trial Researchers from Spain $(n=23)$ and the $\mathrm{UK}(n=7)$, working in the public $(n=22)$, private $(n=1)$, and both public and private $(n=7)$ sectors, gave their consent to and completed the survey. Seventeen were male and 13 female, and the median age was 55.5 years (range 33 to 69 years). Eighty seven percent $(n=26)$ were medical doctors, $10 \%(n=3)$ were nurses, and one respondent did not provide an occupation. The median number of trials respondents had worked on was 6.5 (range 1 to 60 ). Five respondents were members of ethical boards.

The majority of respondents reported that they do not currently use technology to communicate information to research participants at any point in research studies. $36.7 \%$ use technology before the study, $40 \%$ during the study, and $16.7 \%$ after the study. Only $10 \%$ of respondents used technology to attain an electronic signature.

The vast majority (95.5\%) of respondents did not think that new technologies would compromise patient safety. $45.5 \%(n=$ 10) agreed with the statement "I think that new technologies have the potential to speed up the informed consent process", while $45.5 \%(n=19)$ were unsure and $9 \%(n=2)$ thought that technology would slow it down. $78.3 \%(n=18)$ of respondents reported that they thought that technology would be beneficial for standardization. 


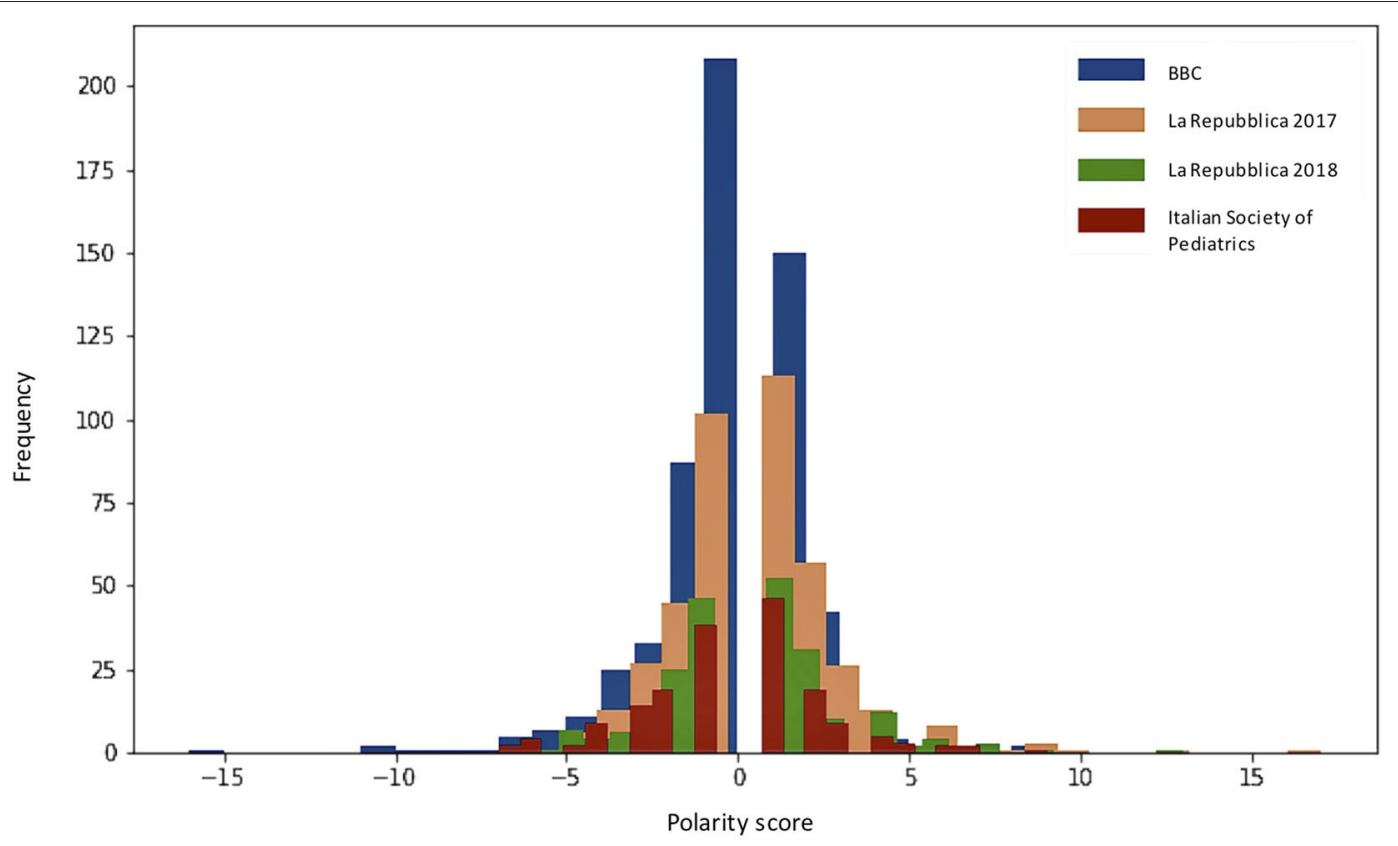

FIGURE 2 | Polarity of comments for each post.

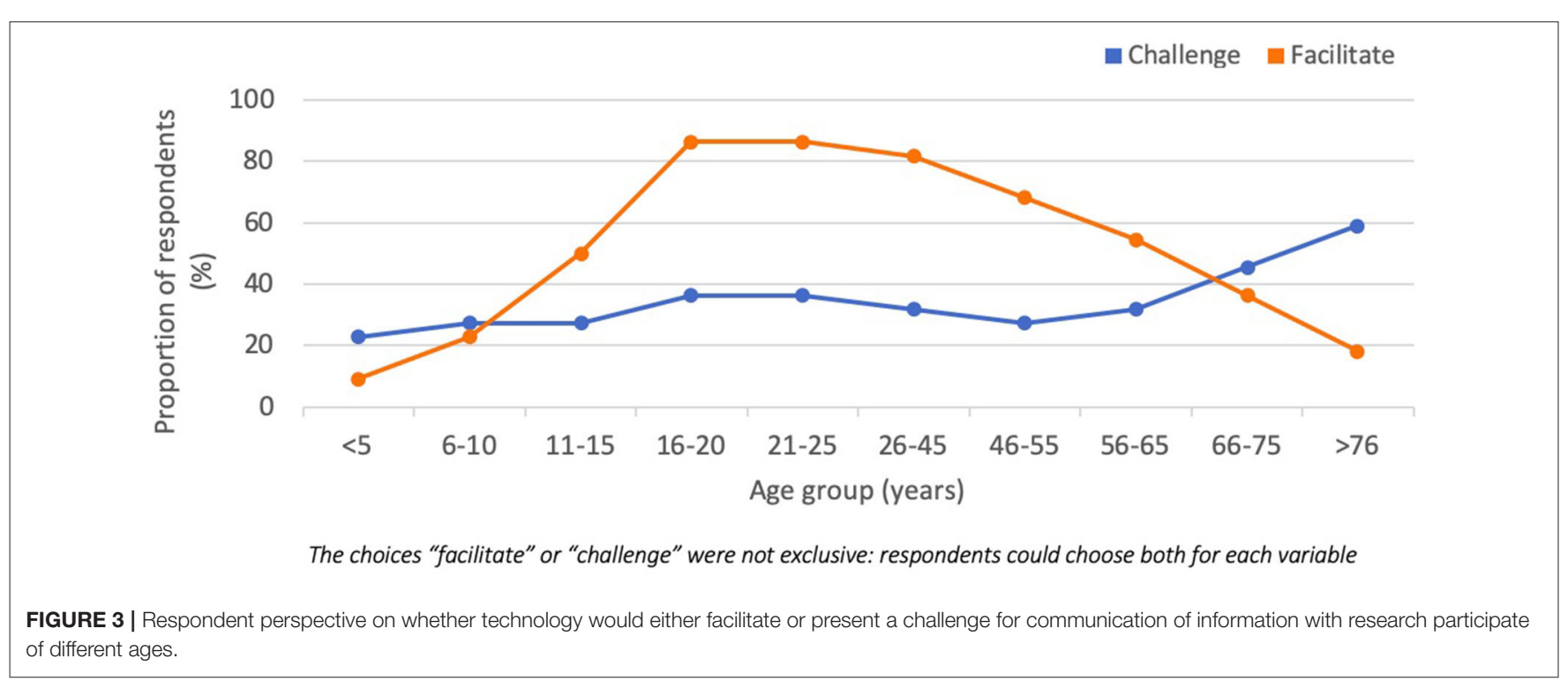

When asked "will technology present a challenge or facilitate the communication of information with different groups of research participants?" respondents perceived that most age-groups would benefit from using technology although challenges were perceived to be bigger than benefits for the $<5$ years and $>75$ years age groups (Figure 3 ). For people with disabilities, respondents perceived that overall, technology would help facilitate communications with people with movement, communication, and social relationship disabilities. More respondents considered that technology could be challenging than facilitating for people with vision, hearing, thinking, learning, mental health, and remembering disabilities. Respondents also considered that technology would present a net-challenge for low income groups, but that it would facilitate communication in medium and high-income groups.

\section{Workshops}

\section{Workshop Group 1: The Lens of Culture}

Participants highlighted that to enable autonomy, having sufficient access to information and time to digest it were crucial. The complexity of the science and language in the original documents was emphasized, and parents noted that they would 
TABLE 2 | Problems and needs as identified by participants.

\begin{tabular}{|c|c|}
\hline Identified problem & Identified need \\
\hline Complex language & Clear language \\
\hline Unclear scientific content & $\begin{array}{l}\text { More background on the specifics e.g., how a virus can cause cancer, how vaccines work, reasons for } \\
\text { reactions, reasons for children requiring vaccination at an age when most are not sexually active, and } \\
\text { reasons for the mention of contraception (required for participation if sexually active) }\end{array}$ \\
\hline Unclear study purpose & $\begin{array}{l}\text { Explanation of who the researchers are } \\
\text { Better explanation of the aim }\end{array}$ \\
\hline $\begin{array}{l}\text { Unclear process, particularly: } \\
\text { - Recruitment method } \\
\text { - Role of the child } \\
\text { - Study withdrawal } \\
\text { - Data access, storage time and anonymization }\end{array}$ & $\begin{array}{l}\text { Description of who the study is targeted at and how the individual was selected } \\
\text { - Clear information about the process for both the parent and child } \\
\text { - Detailed information about the withdrawal process } \\
\text { - More details on the practicalities: when and how data can be accessed by the participant, how long it } \\
\text { will be used, sharing with third parties, and how data could potentially be linked back to participants }\end{array}$ \\
\hline $\begin{array}{l}\text { Insufficient information about alternatives to } \\
\text { trial participation }\end{array}$ & $\begin{array}{l}\text { More explicit details about the other options available outside of the study (for example other HPV } \\
\text { vaccines available in Italy). }\end{array}$ \\
\hline $\begin{array}{l}\text { Insufficient information about risks, particularly: } \\
\text { - Vaccine side effects and how long they may last }\end{array}$ & $\begin{array}{l}\text { More, and clearer information about risks, and about allergies including if and how symptoms for any } \\
\text { unknown allergies may have presented previously }\end{array}$ \\
\hline
\end{tabular}

- Allergies, particularly unknown ones

- Any potential risks to fertility

Unbalanced information (i.e., too much information about privacy)

Coercion through guilt (altruism was noted as a reason for study participation in the invitation letter)

The need to seek information from other sources was expressed

Difficult conversations to have in the family unit

Balance the sections of the informed consent form in line with the patients concerns (less privacy, more health risks)

Clearer, more balanced information about benefits and risks (including separation of individual and societal)

Guidance to good sources of information

Provide materials for communicating with a child on the topic; or communicating with other family members (e.g., husband) seek information from a variety of other sources in addition to the original document. The importance of trust was emphasizedparticipants wondered if their child had been selected on purpose for the study or if participation in the study had been offered generally. A central issue in the discussion was how poor communication due to differences in cultural background between researchers and participants could risk undermining participants' autonomy. The role of a cultural mediator as a third person in the researcher-participant dynamic was considered, particularly in the context of ensuring a woman's voluntariness in cultures where roles are strongly defined by gender.

Concerns raised were common to all participants, regardless of cultural background. Fears around vaccine side-effects, unknown allergies and sexual health generated the most concern. A list of the main problems and corresponding needs identified by participants are provided in Table 2 .

Each of the four participant groups was allocated a topic, and developed a paper prototype (an example is provided in Figure 4) for an interface of their choice. An overview of the prototypes is provided in Table 3.

\section{Workshop Group 2: The Lens of Age}

It became apparent that many opportunities exist to improve the informed consent process, in different areas of the information ecosystem and with different technologies. Participants selected different communication strategies for different severities of disease: they wanted to call a doctor in an emergency, text for less severe health issues, and use an automated form for general Q\&A. From observing interactions between the children and parents, we learned about the family dynamic. The parents assumed an authoritative role in the situation, putting the child patient in a position of less power and autonomy, even though our age range went up to 14 years. We learned which words were not understandable to either the children or their parents, what information they found useful and what they were not interested in knowing. The parents were formal in their communication approach with the doctor-the children more direct.

As researchers, we realized it was necessary to think a lot more broadly about the communication ecosystem than had been done previously. The exercise helped generate a range of ideas from comics, videos, apps, games (board and tech), props (vaccine dolls), through to explore rooms, and websites; highlighting the huge range of possible approaches that could be used to improve communication for informed consent in any setting. When we began to consider desirability, feasibility, and viability, it was quickly apparent that these were context specific, and the "best" choice of approach would vary by setting.

\section{DISCUSSION}

We applied a mixed-methods participatory approach that blended research and design methodologies to address the complex problem of tailoring informed consent for a vaccine clinical trial in our setting, a tertiary pediatric hospital in Rome, Italy. The insights we gained complemented the i-Consent consortium's existing knowledge base, and helped us in the process of developing consent materials. 


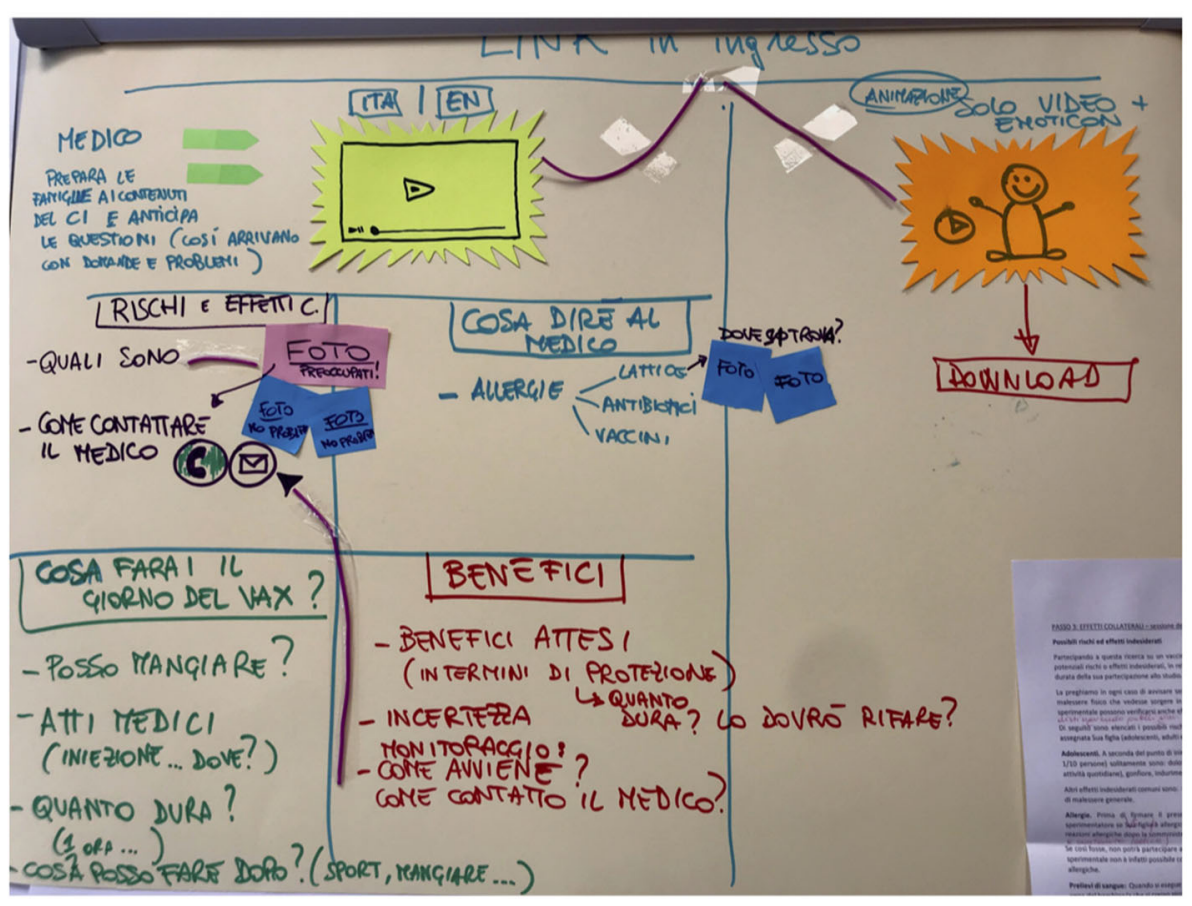

FIGURE 4 | An example of a wireframe prototype on paper.

As is stated in many ethical guidelines and other studies, obtaining informed consent should be an ongoing process in clinical research $(37,38)$ particularly for minors $(39)$. Rather than confining consent to a singular decision or event, we considered informed consent as a continuous, bidirectional communication process that begins at the first contact with the potential participant and continues until the end of the study. We do acknowledge however that for some other scenarios, including neonatal research or emergency consent, the long informed consent process that we envisaged would not necessarily apply (40).

To our knowledge, design thinking has only been used in one other study for the development of the informed consent process. Specifically, DT was used to redesign human research protections, for which informed consent was considered as one of many elements of interest (41). Other studies have explored the adoption of participatory methods for developing informed consent. Recently, a crowdsourcing approach was used to highlight the limits of the informed consent used for HIV clinical trials and propose alternative formats, through workshops that, however, were not based on design thinking (42).

We focused on inclusivity by design (through the lenses of age and culture) to improve participants' comprehension and therefore autonomy, which is crucial to the fulfillment of legal and ethical requirements. Usually, informed consent is not designed with users and frequently does not account for needs which may be based upon factors including education, and societal and cultural differences. We share the widely held view that user participation is of paramount importance to good design, and found that workshops based upon design thinking principles provided us with a good platform for involvement. The participatory approach we took enabled us to modify the content of existing consent materials to the communication needs of users, and generate a variety of prototypes for new tools that patients considered valuable to improve their understanding of all of the information necessary to make an informed decision about clinical trial participation.

Triangulation of methods enabled us to gain a more multidimensional, holistic perspective on the problem, as has been described in other studies (43). Through social media analysis, researchers were able to gain a greater understanding of beliefs, attitudes, and misunderstandings in the community.

Social media analysis has previously been used for investigating the discourse on vaccines on the web (44). Qualitative and quantitative analysis of social media data can provide insights on perceived benefits and on misconception on vaccines, which can serve as a knowledge base to plan the dialogue with patients in the informed consent process for vaccine clinical trials. Natural language processing-based techniques can also be used to identify and analyse social media posts on other drugs or clinical procedures for which an informed consent process is requested. We consider that natural language processing could potentially be a helpful tool to facilitate monitoring changes in community sentiment over time (45), through polarity indicators for example. We attained polarity scores for different posts, but without a larger sample size and validation, these scores remain somewhat arbitrary. We propose that if a baseline were generated with these 
TABLE 3 | An overview of the prototypes developed.

\begin{tabular}{|c|c|c|c|c|}
\hline Prototype group & Interface & Overview of structure & Overview of content & Overview of media \\
\hline \multirow[t]{6}{*}{ 1. Side effects } & $\begin{array}{l}\text { Website - main page links } \\
\text { to either a child or an adult's } \\
\text { site }\end{array}$ & Child. One page & $\begin{array}{l}\text { Basic child's site (one page) } \\
\text { containing a video for download }\end{array}$ & Animation with emoticon \\
\hline & & $\begin{array}{l}\text { Adult. Page split into } 5 \text { main (linked) } \\
\text { sections with link to a sub-page } \\
\text { detailing side effects }\end{array}$ & General information/FAQ & $\begin{array}{l}\text { Video (multilingual) - doctor } \\
\text { providing information }\end{array}$ \\
\hline & & & Risks and side effects of vaccination & $\begin{array}{l}\text { Text description with LINK } \\
\text { to photos; contact details of } \\
\text { doctor (phone/e-mail) }\end{array}$ \\
\hline & & & What to say to the doctor (allergies) & Text description and photos \\
\hline & & & $\begin{array}{l}\text { What to do on the day of the } \\
\text { vaccination }\end{array}$ & Text description \\
\hline & & & Benefits of vaccination & $\begin{array}{l}\text { Text description; LINK to } \\
\text { "contact doctor" }\end{array}$ \\
\hline \multirow[t]{5}{*}{ 2. Privacy } & Mobile phone app & 5 (linked) pages & Why is your consent important? & Text \\
\hline & & & Who is holding my information? & $\begin{array}{l}\text { Text and link to OPBG and } \\
\text { vaccine society websites }\end{array}$ \\
\hline & & & $\begin{array}{l}\text { Are you free to withdraw from } \\
\text { participating? }\end{array}$ & $\begin{array}{l}\text { Link to details on how to } \\
\text { withdraw }\end{array}$ \\
\hline & & & Can I have access to my data? & Text and link to OPBG \\
\hline & & & $\begin{array}{l}\text { Check that everything is understood } \\
\text { and consent }\end{array}$ & Checkbox \\
\hline \multirow[t]{5}{*}{$\begin{array}{l}\text { 3. Vaccine } \\
\text { administration }\end{array}$} & Paper or phone app & Text split into 5 sections, and calendar & $\begin{array}{l}\text { Introduction explaining where the } \\
\text { vaccine is being administered }\end{array}$ & Text \\
\hline & & & $\begin{array}{l}\text { When and how is the vaccine } \\
\text { administered? }\end{array}$ & Text \\
\hline & & & How will analyses be done? & Text \\
\hline & & & Calendar & Calendar \\
\hline & & & Next contact with researchers & Text \\
\hline \multirow[t]{5}{*}{ 4. Sexual health } & Paper & Text with 5 headings & What is HPV? & Text \\
\hline & & & The vaccine & Text \\
\hline & & & Who should be vaccinated? & Text \\
\hline & & & Contraindications & Text \\
\hline & & & To participate in the study & Text \\
\hline
\end{tabular}

indicators, this technique could potentially be used to monitor the "temperature" of a topic in the population over time, and that this could be an interesting area for future research.

At present, social media analysis is usually based on text extracted from posts that are openly available to the public, and, given the peculiar nature of this kind of research, no consent is asked to the authors of the posts. Ethical aspects on the use of digital data, especially regarding minors, have recently been addressed in a scoping review (46), which highlighted a degree of uncertainty regarding the ethics of this kind of research, and suggested the use of participatory and co-production practices to address these issues together with the population targeted by each study.

A survey provided insights on the perspective and attitudes of researchers to using technological tools for informed consent. While the use of technology or innovative tools for the consent process was limited among the participants, most respondents deemed the use of technology for informed consent as safe, which suggests a potentially high level of acceptability of innovative methods for consent. On the other hand, almost half of respondents were uncertain about the potential of technological tools to speed up the informed consent process. This result points out that more research is needed on the impact of innovative solutions on the time for acquisition of informed consent, which is a rarely considered dimension.

Researchers surveyed identified some groups as potentially finding technology challenging, for example very young children or patients with vision or hearing disabilities. While it was considered that technology could present a challenge to some of these users, it is immediately evident that technology could be a big enabler for access: for example, for those with visual disabilities a range of options including text-to-speech could be utilized whereas those with hearing disabilities would benefit from more visual content. The result might be more indicative of the survey respondents personal experience-the technology they use on a day-to-day basis-than the full range of what is actually available on the market. In any case, this result suggests, on one hand, the need to include people with disabilities in the 
development of informed consent processes and, on the other hand, the need for more specific education of researchers on the potential of technology for improving accessibility to information for people with disabilities.

Based on the insights gained through the social media analysis and the survey, particularly about potential areas of sensitivity and discordant views, researchers were better prepared to facilitate balanced dialogue from different perspectives during the workshops. In the workshops, while it was clear that needs differed between adults and children, it was also clear from involving participants from different cultures that core human needs such as autonomy were the same for all informed consent users regardless of perceived cultural differences.

While we were able to make immediate modifications to the content of the existing informed consent documentation in our setting, we didn't develop final products for the prototypes of the more disruptive and innovative ideas generated. While we consider that these ideas would enable us to implement informed consent with more impact, their deployment would necessitate process change and our ability to deploy them is highly dependent upon other decision-making factors including available funding. Improving communications in the recruitment phase does have the potential to have reap returns on investment given that randomized controlled trials are very costly to implement, and many do not meet their recruitment targets (47-49).

We feel that this approach gave us an excellent basis upon which to move forward: with the patient's needs and wants clearly stated, we can now scope the existing products on the market in a more targeted way. For the products that do not yet exist, these prototypes provide us with clarity, and therefore a stronger basis upon which we can begin discussions and form collaborations with partners to develop final products. The approach that we developed in Rome has already been utilized by our i-Consent consortium partner, FISABIO in Valencia, Spain, to develop an informed consent communication tool tailored to context (50).

This work has taken on additional relevance since the emergence of SARS-CoV-2 because research on novel vaccines has accelerated globally, and children will need to be included

\section{REFERENCES}

1. The Council of Europe, Additional Protocol to the Convention on Human Rights and Biomedicine, Concerning Biomedical Research. ETS No. 195. Available online at https://www.coe.int/en/web/conventions/full-list/-/ conventions/treaty/195

2. Regulation (EU) No 536/2014 of the European Parliament and of the Council of 16 April 2014 on Clinical Trials on Medicinal Products for Human Use, and Repealing Directive 2001/20/EC. Available online at: https://eur-lex.europa.eu/ legal-content/EN/TXT/PDF/?uri=CELEX:32014R0536\&from=IT

3. Albala I, Doyle M, Appelbaum PS. The evolution of consent forms for research: a quarter century of changes. IRB. (2010) 32:7-11.

4. Berger O, Grønberg BH, Sand K, Kaasa S, Loge JH. The length of consent documents in oncological trials is doubled in twenty years. Ann Oncol. (2009) 20:379-85. doi: 10.1093/annonc/ mdn623 in vaccine trials (51). Vaccine trial recruitment can be affected by potential participants' existing beliefs and misconceptions, and vaccination is a sensitive and politicized issue for which members of a community can have polarized views, particularly with the advent of the internet and social networks (52). Beliefs and misconceptions about vaccines are not static in the community, and our scientific understanding is also progressing at a rapid pace-particularly in the context of coronavirus. Informed consent will need to evolve over time along with the information ecosystem, and we consider that an approach inspired by design thinking could enable rapid adaptation to local needs to be conducted to keep pace.

\section{CONCLUSION}

We propose using a participatory, mixed-methods approach to design informed consent so that it is better adapted to patients' needs. Such an approach would be helpful in better addressing the needs of different segments of the populations involved in clinical trials. Further evidence should be gained about the impact of this strategy in improving recruitment, decreasing withdrawals and litigations, and improving patient satisfaction during clinical trials.

\section{AUTHOR CONTRIBUTIONS}

SJ, MD, SLP, and AET all made substantial contributions to the conception or design of the work, the acquisition, analysis or interpretation of data for the work, and drafting the work or revising it critically for important intellectual content. FG reviewed the original manuscript, improved its final structure, and helped developing the discussion.

\section{FUNDING}

This research was funded by Horizon 2020 SwafS-17-2016 GA n.741856 and conducted in the framework of the European project Improving the guidelines for Informed Consent, including vulnerable populations, under a gender perspective.
5. Tarnowski KJ, Allen DM, Mayhall C, Kelly PA. Readability of pediatric biomedical research informed consent forms. Pediatrics. (1990) 85:58-62.

6. Jefford $M$, Moore R. Improvement of informed consent and the quality of consent documents. Lancet Oncol. (2008) 9:48593. doi: 10.1016/S1470-2045(08)70128-1

7. With Patients at the Age of Development, With Cognitive Competences, Thoughts and Feelings Evolving, The Ethical Risk of Directing the Information Towards the Obtaining of Consent and of Mistaking Assent for Consent Is Much Higher. Italian Committee for Bioethics, Information and Consent Related to Medical Treatment (1992). Available online at: http://bioetica.governo.it/en/ opinions/opinions-responses/information-and-consent-related-to-medicalacts/)

8. The Nuffield Council on Bioethics, Children and Clinical Research: Ethical Issues. (2015). Available online at: https://www.nuffieldbioethics.org/wpcontent/uploads/Children-and-clinical-research-full-report.pdf

9. Palazzani L. Bioethics and Biolaw: Theories and Questions. Turin: Giappichelli (2018).p. 141. 
10. Regulation (EC) No 1901/2006 of the European Parliament and of the Council of 12 December 2006 on Medicinal Products for Paediatric Use. Available online at: https://ec.europa.eu/health//sites/health/files/files/eudralex/vol-1/reg_20 06_1901/reg_2006_1901_en.pdf

11. Joseph PD, Craig JC, Caldwell PH. Clinical trials in children. Br J Clin Pharmacol. (2015) 79:357-69. doi: 10.1111/bcp.12305

12. Medical Research Council. MRC Ethics Guide: Medical Research Involving Children. London: MRC (2004).

13. Regulation (EC) No 1902/2006 of the European Parliament and of the Council of 20 December 2006 Amending Regulation 1901/2006 on Medicinal Products for Paediatric Use. Available online at: https://ec.europa.eu/health//sites/health/files/files/eudralex/vol-1/reg_20 06_1902/reg_2006_1902_en.pdf

14. The Council of Europe, Convention for the Protection of Human Rights and Dignity of the Human Being With Regard to the Application of Biology and Medicine: Convention on Human Rights and Biomedicine. (1997). Available online at: https://www.coe.int/en/web/conventions/fulllist/-/conventions/treaty/164

15. Fons-Martínez J, Calvo Rigual F, Díez-Domingo J, Nepi L, Persampieri LCFA. Contents of the Minor's Assent in Medical Research: Differences between the Scientific Literature and the Legal Requirements. Rivista di BioDiritto (2019).

16. Ballard HO, Shook LA, Iocono J, Bernard P, Hayes D Jr. Parents' understanding and recall of informed consent information for neonatal research. IRB. (2011) 33:12-9.

17. Shilling V, Young B. How do parents experience being asked to enter a child in a randomised controlled trial? BMC Med Ethics. (2009) 10:1. doi: 10.1186/1472-6939-10-1

18. Dahan S, Jung C, Dassieu G, Durrmeyer X, Caeymaex L. Trust and consent: a prospective study on parents' perspective during a neonatal trial. J Med Ethics. (2020) doi: 10.1136/medethics-2019105597

19. PREPRINT. Digital tools in the informed consent process: a systematic review. BMC Med Ethics. (2020).

20. Bossert S, Kahrass H, Heinemeyer U, Prokein J, Strech D. Participatory improvement of a template for informed consent documents in biobank research - study results and methodological reflections. BMC Med Ethics. (2017) 18:78. doi: 10.1186/s12910-017-0232-7

21. Ferreira FK, Song EH, Gomes H, Garcia EB, Ferreira LM. New mindset in scientific method in the health field: Design Thinking. Clinics. (2015) 70:770-2. doi: 10.6061/clinics/2015(12)01

22. Brown T. Design thinking. Harv Bus Rev. (2008) 86:141

23. Roberts JP, Fisher TR, Trowbridge MJ, Bent C. A design thinking framework for healthcare management and innovation. Healthc (Amst). (2016) 4:114. doi: 10.1016/j.hjdsi.2015.12.002

24. Meinel C, Leifer L. Design thinking research. In: Plattner H, Meinel C, Leifer L, editors. Design Thinking Research: Studying Co-Creation in Practice. Berlin; Heidelberg:Springer-Verlag. (2012). doi: 10.1007/978-3-64213757-0

25. Bazzano AN, Martin J, Hicks E, Faughnan M, Murphy L. Humancentred design in global health: a scoping review of applications and contexts. PLoS ONE. (2017) 12:e0186744. doi: 10.1371/journal.pone. 0186744

26. Altman M, Huang TTK, Breland JY. Design thinking in health care. Prev Chronic Dis. (2018) 15:E117. doi: 10.5888/pcd15. 180128

27. Hendricks S, Conrad N, Douglas TS, Mutsvangwa T. A modified stakeholder participation assessment framework for design thinking in health innovation. Healthc (Amst). (2018) 6:191-196. doi: 10.1016/j.hjdsi.2018. 06.003

28. Björgvinsson, E, Ehn, P, Hillgren PA. Design things and design thinking: contemporary participatory design challenges. DesignIssues. (2012) 28:10117. doi: 10.1162/DESI_a_00165

29. Orlowski S, Matthews B, Bidargaddi N, Jones G, Lawn S, Venning A, et al. Mental health technologies: designing with consumers. JMIR Hum Factors. (2016) 3:e4. doi: 10.2196/humanfactors.4336

30. Vechakul J, Shrimali BP, Sandhu JS. Human-centered design as an approach for place- based innovation in public health: a case study from Oakland, California. Matern Child Health J. (2015) 19:25529. doi: 10.1007/s10995-015-1787-x

31. IDEO. IDEO Design Thinking: Design Thinking Defined [Internet]. Available online at: https://designthinking.ideo.com/ (accessed October 7, 2020).

32. Sanchez-Burks J. Design Thinking: Sampling Extreme Users. National Arts Strategies [Internet]. Available online at: https://www.youtube.com/watch?v= G4wC2GGINWI (accessed October 7, 2020).

33. Stanford Design School. Method: Extreme Users [Internet]. Available online at: https://dschool-old.stanford.edu/wp-content/themes/dschool/methodcards/extreme-users.pdf (accessed October 7, 2020).

34. Jünger J, Keyling T. Facepager. An Application for Automated Data Retrieval on the Web. [Internet]. Source code and releases available online at https://github.com/strohne/Facepager/ (accessed October 7, 2020).

35. Kelley T. Build Your Creative Confidence: Empathy Maps [Internet]. IDEO Blog. (2018) Available online at: https://www.ideo.com/blog/build-yourcreative-confidence-empathy-maps (accessed October 7, 2020).

36. IDEO. Brainstorm Rules. Design Kit. [Internet]. IDEO.org. Available online at: https://www.designkit.org/methods/brainstorm (accessed October 7, 2020).

37. Council of International Organizations of Medical Sciences (CIOMS), International Ethical Guidelines for Health-Related Research Involving Humans, Commentary on Guideline 9 ("Individuals capable of giving informed consent”). (2016). Available online at https://cioms.ch/wp-content/uploads/ 2017/01/WEB-CIOMS-EthicalGuidelines.pdf

38. Allmark P, Mason S. Improving the quality of consent to randomised controlled trials by using continuous consent and clinician training in the consent process. J Med Ethics. (2006) 32:439-43. doi: 10.1136/jme.2005. 013722

39. Katz AL, Webb SA, Committee on Bioethics. Informed consent in decision-making in pediatric practice. Pediatrics. (2016) 138:e20161485. doi: 10.1542/peds.2016-1485

40. Janvier A, Farlow B. The ethics of neonatal research: An ethicist's and a parents' perspective. Semin Fetal Neonatal Med. (2015) 20:43641. doi: 10.1016/j.siny.2015.10.003

41. Bloss C, Nebeker C, Bietz M, Bae D, Bigby B, Devereaux M, et al. Reimagining human research protections for 21 st century science. J Med Internet Res. (2016) 18:e329. doi: 10.2196/ jmir.6634

42. Day S, Mathews A, Blumberg M, Vu T, Rennie S, Tucker JD. Broadening community engagement in clinical research: Designing and assessing a pilot crowdsourcing project to obtain community feedback on an HIV clinical trial. Clin Trials. (2020) 17:306-13. doi: 10.1177/1740774520 902741

43. Denzin NK. The Research Act: A Theoretical Introduction to Sociological Methods (2nd ed.). New York, NY: McGraw-Hill. (1978).

44. European Centre for Disease Prevention and Control. Systematic Scoping Review on Social Media Monitoring Methods and Interventions Relating to Vaccine Hesitancy. Stockholm: ECDC (2020).

45. Luo X, Zimet G, Shah S. A natural language processing framework to analyse the opinions on HPV vaccination reflected in twitter over 10 years (2008 - 2017). Hum Vaccin Immunother. (2019) 15:1496504. doi: 10.1080/21645515.2019.1627821

46. Facca D, Smith MJ, Shelley J, Lizotte D, Donelle L. Exploring the ethical issues in research using digital data collection strategies with minors: a scoping review. PLoS ONE. (2020) 15:e0237875. doi: 10.1371/journal.pone. 0237875

47. Treweek S, Lockhart P, Pitkethly M, Cook JA, Kjeldstrøm M, Johansen $M$, et al. Methods to improve recruitment to randomised controlled trials: cochrane systematic review and meta-analysis. BMJ Open. (2013) 3:e002360. doi: 10.1136/bmjopen-2012002360

48. Carlisle B, Kimmelman J, Ramsay T, MacKinnon N. Unsuccessful trial accrual and human subjects protections: an empirical analysis of recently closed trials. Clin Trials. (2015) 12:77-83. doi: 10.1177/1740774514 558307 
49. Wood AM, White IR, Thompson SG. Are missing outcome data adequately handled? A review of published randomized controlled trials in major medical journals. Clin Trials. (2004) 1:368-76. doi: 10.1191/1740774504 cn032oa

50. I-CONSENT. i-CONSENT Involves Children in the Project Through Design Thinking [Internet]. (2019). Available online at: https://i-consentproject.eu/ i-consent-project-involves-children-in-its-investigations-through-designthinking/ (accessed October 7, 2020).

51. World Health Organization. Draft Landscape of COVID-19 Candidate Vaccines. WHO (2020).

52. Zollo F. Dealing with digital misinformation: a polarised context of narratives and tribes. EFSA J. (2019) 17(Suppl 1):e170720. doi: 10.2903/j.efsa.2019.e170720
Conflict of Interest: SLP was employed by the company AND Consulting Group.

The remaining authors declare that the research was conducted in the absence of any commercial or financial relationships that could be construed as a potential conflict of interest.

Copyright (c) 2021 Jackson, Daverio, Perez, Gesualdo and Tozzi. This is an openaccess article distributed under the terms of the Creative Commons Attribution License (CC BY). The use, distribution or reproduction in other forums is permitted, provided the original author(s) and the copyright owner(s) are credited and that the original publication in this journal is cited, in accordance with accepted academic practice. No use, distribution or reproduction is permitted which does not comply with these terms. 